Баско Олег Викторович

кандидат экономических наук, доцент кафедры банковского дела Ростовского государственного экономического университета

\section{БАНКОВСКОЕ ОБСЛУЖИВАНИЕ В РОССИИ В УСЛОВИЯХ PАСПРОСТРАНЕНИЯ COVID-19}

Аннотация:

Автором проведено исследование особенностей банковского обслуживания в условиях распространения коронавирусной инфекции. Отмечается, что эпидемия Covid-19 закрепила за банковской сферой функции контроля и координации мер поддержки бизнеса со стороны государства, направленных на выход из кризиса. Наряду с ориентацией правительственной финансовой политики на устойчивое развитие экономики страны, утверждение пакета поддерживающих ее мер, частные банковские структуры самостоятельно предприняли ряд шагов по сокращению собственных потерь, связанных с распространением новой коронавирусной инфекции, а также по расширению клиентской базы с целью роста финансовых вложений. Делается вывод, что ситуация в банковской сфере современной России в условиях пандемuи Covid-19 развивается полинаправлено. C одной стороны, банки являются проводниками государственных мер поддержки населения, а с другой - вынуждены бороться за собственное существование вследствие резкого падения уровня финансовых вливаний. Такое положение дел обуславливает и специфику банковского обслуживания граждан и организаций. Для него характерны: тенденция к дистанцированию банковского взаимодействия с клиентом, разработка новых методов и способов защиты удаленных финансовых операций, борьба за привлечение новых клиентов с целью обеспечения пополнения фондов, разработка новых предложений по продажам банковских продуктов, расширение спектра услуг.

Ключевые слова

банк, обслуживание, коронавирус, пандемия, эпидемия, бизнес, клиент, поддержка, рынок, экономика, дистанционный, система, мошенничество, мероприятия, прибыль.
Basko Oleg Viktorovich

PhD in Economics Associate Professor, Banking Department, Rostov State University of Economics

\section{BANKING SERVICES IN RUSSIA IN THE CONTEXT OF THE SPREAD OF COVID-19}

\section{Summary:}

The author conducted a study of the features of banking services in the conditions of the spread of coronavirus infection. It is noted that the Covid-19 epidemic has assigned the functions of monitoring and coordinating measures in the banking sphere to support business by the state aimed at overcoming the crisis. Along with the direction of the government financial policy towards the sustainable development of the economy of the country and the approval of a package of supporting measures, private banking structures have independently taken a number of steps to reduce their own losses due to with the spread of a new coronavirus infection, as well as to expand the client base in order to increase financial in vestments. It is concluded that the situation in the banking sector of modern Russia in the context of the Covid19 pandemic is developing in a multidirectional way. On the one hand, banks are the agents of state measures to support the population, and on the other one, hey are forced to struggle for their own existence due to a sharp drop in the level of financial injections. This state of affairs also determines the specifics of banking services for individuals and organizations. It is characterized by a tendency to distance banking customer interactions, developing new methods and ways of protection of remote financial transactions, attracting new customers to en sure the development of collections, development of new proposals for sales of banking products, expanding the range of services.

Keywords:

bank, service, coronavirus, pandemic, epidemic, business, customer, support, market, economy, remote, system, fraud, activities, profits.

В 2020 году всемирная экономика впервые испытала ффинансово-экономический кризис, причиной которого стали не ошибки и сбои в работе рыночной системы, а парализация экономического роста стран вследствие невозможности участия в нем человеческого фактора ввиду массового поражения людей коронавирусной инфекцией либо действия государственных ограничительных мер с целью сдерживания распространения вируса.

Пандемия Covid-19 стала большим испытанием и для российской экономики. Банковская сфрера страны является одним из основополагающих элементов фринансовой системы государства, включая ее безопасность. Оборот денежных средств напрямую не связан с распространением вируса, однако ввиду сопряженности финансовых операций с очными или заочными контактами граждан, банковская сфера является объектом повышенного риска для современного общества [1]. Кроме того, банковские услуги для бизнеса, в частности наиболее распространенные из них - расчетно-кассовое обслуживание, зарплатные проекты, кредитные линии, обеспечивают жизнеспособность на экономической арене любой организации, фирмы или предприятия. 
Все сказанное свидетельствует о важности банковской сфреры для показателей экономики страны и сохранения ее финансового равновесия в условиях пандемии.

Распространение коронавирусной инфекции и введение правительством России ограничительных мер для граждан привело к массированному оттоку денежных средств из банковской сореры и, следовательно, из экономики страны. Огромное количество потребителей банковских услуг осталось без возможности реализации своих экономических потребностей ввиду соблюдения режима самоизоляции, нахождения на карантине либо лечения в медицинских учреждениях. У многих граждан возникли сложности с выплатой кредитов, ипотечных взносов. Более того, бизнес-кредиты, выданные малым и средним организациям, оказались под угрозой невозвращения вследствие невозможности работы этих фирм в условиях пандемии и неполучения ими прибыли, из средств которой предприниматели ранее выплачивали кредит.

Убыточными в период распространения коронавирусной инфекции стали многие отрасли российской экономики, причем возможность компенсации потерянных денежных средств в будущем остается весьма призрачной. В частности, розничная торговля и производство испытали в период эпидемии огромный спад, однако при увеличении числа потребителей нельзя исключать и возможный рост финансовой прибыли подобных предприятий [2].

При этом хотелось бы отметить, что и в России, и на международном уровне организована финансовая помощь бизнесу со стороны банков. К примеру, в ближайшее время из бюджета Европейского союза Европейскому инвестиционному фонду будет направлено 10 млрд евро в качестве обеспечительных мер внешней поддержки, благодаря которой будет осуществлено воздействие на ликвидность малого, среднего бизнеса, а также средних предприятий [3].

Кроме того, Европейским центральным банком (ЕЦБ) было объявлено о снятии ряда ограничений, действующих ранее в условиях «пандемического шока». Для поддержки малого и среднего бизнеса коммерческим банкам со стороны ЕЦБ будут предоставляться займы, ставки по которым будут значительно ниже тех, что предлагались до пандемии. В частности, некоторые из них могут составлять менее 1 процента.

21.03.2020 правительством Российской Федерации был утвержден «План первоочередных мероприятий (действий) по обеспечению устойчивого развития экономики в условиях ухудшения ситуации в связи с распространением новой коронавирусной инфекции» [4]. Материальный фронд его включает 300 млрд рублей. Хотелось бы заметить, что в случае, если пандемией будет вызван критический спад экономики, следствием которого станет дефолт, безработица, гибель людей, то фонды оказания помощи и денежные стимулирования в рамках страны окажутся бесполезными - экономика потребует значительных финансовых вливаний.

В соответствии с обозначенным планом необходимо увеличение программы выдачи кредитов на льготных условиях, а также осуществление возможности реструктуризации выданных ранее займов с предоставлением более выгодных ставок [5].

Необходимо, чтобы клиенты понимали, что финансовая поддержка (так называемые «кредитные каникулы») гражданам и организациям может быть доступна лишь непродолжительное время [6]. В противном случае сама банковская система станет убыточной. Кроме того, другим условием успешной реализации рассматриваемого плана является отсутствие у банков, участвующих в государственной программе помощи населению, проблем с ликвидностью и, следовательно, с возможностью предоставления гражданам «кредитных каникул» вследствие удержания низких процентных ставок. При этом банки должны учитывать совокупность сведений об области риска, его индикаторах, а также о применении необходимых мер по предотвращению или минимизации неблагоприятных последствий, так как процентные платежи по кредитным линиям являются важной составляющей их доходов.

Угроза распространения коронавирусной инфекции требует перестройки механизмов социального взаимодействия. Сказанное касается и банковской системы: сотрудники и бизнес-клиенты фринансовых и кредитных организаций, а также вкладчики и потребители банковских продуктов должны быть защищены от коронавирусной инфекции при необходимости воспользоваться сервисами и услугами банковской сферы. В связи с этим большинство организаций активно воспользовались возможностями перевода сотрудников на удаленную форму работы, позволяющую не только обеспечить нормальное функционирование отлаженной системы продаж и предоставления услуг, хоть и в дистанционном формате, но и значительно сэкономить (например, на аренде офисов или оплате коммунальных услуг). Для бизнес-клиентов, вкладчиков и рядовых граждан необходимость личного присутствия при взаимодействии с банковской сферой услуг также стала нежелательна ввиду угроз со стороны Covid-19: для большинства из них предпочтительно удаленное взаимодействие с банковскими структурами без какого-либо физического участия в коммуникации, но, естественно, и без ограничений доступа к возможностям финансовой системы банка [7]. 
В этих условиях при осуществлении удаленных транзакций актуальным стало обеспечение их безопасности для обеих сторон-участниц. Особая обеспокоенность банков в условиях перехода на дистанционное обслуживание была вызвана увеличением количества кибератак и мошенничества, связанных с возможностью использования в преступных целях недостаточной защищенности электронных личных данных граждан, а также несовершенством имеющейся системы контроля за удаленными операциями. Кроме того, сами клиенты и сотрудники банковских организаций только начали приспосабливаться к новой среде взаимодействия, поэтому не всегда соблюдают необходимые меры предосторожности в отношении сохранения сведений о наличии финансовых средств на счетах, что зачастую приводит к неблагоприятным последствиям (например, утрате вложений ввиду доступности банковских данных о кредитных и дебетовых картах третьим лицам и т. д.).

Очевидно, что рост числа удаленных банковских операций не должен отрицательно сказываться на их качестве: в интересах банков гарантировать, что и повседневные, и исключительные финансовые манипуляции будут выполняться с минимальным количеством нарушений [8].

Интересен опыт мировой банковской системы по защите денежных средств в условиях коронавирусной пандемии. Например, Банк Кореи стал помещать счета местных банков на карантин сроком до 14 дней. Подобным образом поступило и правительство КНР, попросив кредиторов провести ревизию своих физических записей [9]. В США введена практика дезинфекции и изоляции денежных банкнот, поступающих из Азии, сроком от 7 до 10 дней.

Распространение вируса по всему миру привело к тому, что бизнес-заемщики столкнулись с потерей рабочих мест, уменьшением продаж и снижением финансовой прибыли. Бизнес-клиенты непрерывно ищут источники для получения финансовой помощи, а регуляторы федеральных (национальных) банков побуждают коммерческие банки выступать в роли финансового гаранта [10].

В России поддержка бизнеса со стороны государства посредством банковских инструментов носит не совсем однозначный характер. Наряду с ориентацией правительственной фринансовой политики на устойчивое развитие экономики страны, утверждение пакета поддерживающих ее мер, частные банковские структуры самостоятельно предприняли ряд шагов по сокращению собственных потерь, связанных с распространением новой коронавирусной инфекции. Так, вместо, казалось бы, логичной отмены сборов по платежам Сбербанк, наоборот, ввел комиссию за перевод денежных средств. Предоставление отсрочки ипотечных платежей для бизнеса и доступа к фиксированным счетам для тех, кто пострадал от коронавирусной инфекции, анонсированное правительством как мера поддержки экономики, сегодня носит скорее формальный, чем реальный характер [6].

Кроме того, некоторые коммерческие банки ужесточили требования к ПОД-ФТ (противодействие отмыванию доходов и финансированию терроризма), массово блокируя счета предпринимателей и вынуждая их заниматься длительными разбирательствами, во время которых находящиеся на таких счетах денежные средства являются, по сути, изъятыми из экономики страны, так как они не могут участвовать в финансовом обороте.

Таким образом, российское банковское обслуживание в условиях пандемии, несмотря на попытки правительства использовать его как инструмент поддержки экономики страны в целом и граждан в частности, оставаясь в руках частных лиц, является ориентированным на личную выгоду владельцев коммерческих банков.

Однако поскольку рынок банковских услуг является сегодня важнейшим сектором экономики страны, главная его задача сейчас заключается в результативной рекомбинации фринансовых ресурсов между клиентами, субъектами хозяйствования и государством с целью обеспечения их поддержки в период пандемии коронавирусной инфекции. Аккумуляция финансов в банковской системе требует ее постоянного развития. Следовательно, необходимо разработать ряд мер по поддержке собственно финансовых организаций.

Для поддержки бизнеса банкам следует:

1. Использовать все возможности для увеличения числа клиентов, в том числе расширять спектр цифровых и дистанционных услуг. Пандемия является ускоряющим механизмом использования технологий дистанционного банковского обслуживания, а также новых методов взаимодействий клиентов с банками. При этом внедрение систем цифрового учета часто провоцирует и негативные эффекты: клиенты банковских организаций вынуждены проводить по нескольку часов на улице перед отделением в ожидании своей очереди (например, такие факты наблюдались в Газпромбанке). В этом случае проблема безопасности обслуживания особенно обостряется, а механизмы цифрового взаимодействия требуют доработки.

2. Осуществлять полноценный финансовый консалтинг с учетом современной ситуации. Банки могут предоставить своим клиентам новые возможности посредством дистанционных консультаций, а также предложить бухгалтерские и налоговые услуги. 
3. Проводить поддержку клиентов посредством положительных решений по реструктуризации займов и предложений использования альтернативных банковских продуктов.

В заключение следует сказать, что ситуация в банковской сфере современной России в условиях пандемии Covid-19 развивается полинаправлено. С одной стороны, банки являются проводниками государственных мер поддержки населения, а с другой - вынуждены бороться за собственное существование вследствие резкого падения уровня финансовых вливаний. Такое положение дел обуславливает и специфику банковского обслуживания граждан и организаций. Для него характерны: тенденция к дистанцированию банковского взаимодействия с клиентом, разработка новых методов и способов защиты удаленных фринансовых операций, борьба за привлечение новых клиентов с целью обеспечения пополнения фондов, разработка новых предложений по продажам банковских продуктов, расширение спектра услуг. В целом можно сказать, что, несмотря на стагнацию в современной экономике страны, банковская система России продолжает свое развитие, а условия распространения коронавирусной инфекции дали толчок для совершенствования банковского обслуживания и поиска новых возможностей для взаимодействия с клиентом.

\section{Ссылки:}

1. Попова И.Н., Пономарев А.П. Проблемы банковской деятельности в условиях пандемии // StudNet. 2020. № 8. C. 29-36.

2. Асеев О.В., Машкина Н.А., Велиев А.Е. Банковская система реального сектора экономики в условиях неопределенности // Вестник Курской государственной сельскохозяйственной академии. 2019. № 1. С. 141-146.

3. Рындина И.В., Чонка А.А. Реструктуризация банковского сектора в условиях кризиса 2020 года // StudNet. 2020. T. 3. № 8. С. 598-604.

4. Шагинян T.B. Социально-экономические последствия пандемии COVID-19 // Новые экономические исследования. Пенза, 2020. С. 73-75.

5. Там же.

6. Щурина С.В. Меры поддержки субъектов малого и среднего предпринимательства в приоритетных отраслях российской экономики в 2020 году // Экономика. Налоги. Право. 2020. № 1. С.

7. Данилович В.Ю. Российская банковская система в условиях санкций - проблемы и вызовы // Бизнес-образование в экономике знаний. 2016. № 3 (5). С. 12-15 ; Зюкин Д.В. COVID-19 или рестарт экономики // Наука и практика регионов. 2020. № 1 (18). С. 74-80.

8. Михеева Н.П. Наращивание капитала банков в условиях кризиса // Вестник Оренбургского государственного университета. 2015. № 8 (183). С. 104-110 ; Таштамиров М.Р. Тенденции развития банковской системы и ее устойчивости в условиях негативной экономической конъюнктуры [Электронный ресурс] // Науковедение: интернет-журнал. 2017. T. 9. № 1. C. 1-16. URL: https://naukovedenie.ru/PDF/92EVN117.pdf (дата обращения: 25.06.2020).

9. Симэн Е., Шерешева М.Ю. Государственная политика КНР в отношении китайских малых и средних предприятий в условиях пандемии COVID-19 [Электронный ресурс] // Государственное управление. Электронный вестник. 2020. № 79. С. $25-50$.

10. Закирова Д.Ф., Закирова Е.Ф. Оценка влияния экономических санкций на банковскую систему Российской Федерации // Актуальные проблемы экономики и права. 2018. Т. 12. № 1. С. 19-32. https://doi.org/10.21202/1993047X.12.2018.1.19-32.

Редактор: Ситникова Ольга Валериевна Переводчик: Кочетова Дарья Андреевна 